\title{
Explaining Fictional Characters
}

\author{
TATJANA VON SOLODKOFF \\ University College Dublin
}

\begin{abstract}
Fictional characters are awkward creatures. They are described as being girls, detectives, and cats; as being famous, based on real people, and well developed, and as being paradigmatic examples of things that don't exist. It's not hard to see that there are tensions between these various descriptions-how can something that is a detective not exist? - and there is a range of views designed to make sense of the pretheoretical data. Fictional realists hold that we should accept that fictional characters are part of 'the furniture of our world'. Others are fictional anti-realists, who hold instead that our world does not contain any such things. In this article, I deploy an independently motivated metaontology to defend a novel version of fictional antirealism. On the view I develop and defend, the central task we face is that of explaining facts concerning fictional characters, where the relevant notion of explanation is distinctively metaphysical in character. Fictional anti-realism emerges as the plausible thesis that facts about fictional entities can be completely explained in terms of the existence and features of other things.
\end{abstract}

$\mathrm{F}$ ICTIONAL characters are awkward creatures. They are described as being girls, detectives or cats in their home fictions, but who of us has ever met Hermione Granger, Sherlock Holmes or the Cheshire Cat? No one, of course: they are, after all, not real. Given that no one has ever come across them, given that we can neither see nor touch them, maybe fictional characters are nothing more than shadows cast by our linguistic projections onto the world, a world that is really free of such objects.

Some philosophers, however, are very fond of Holmes and his ilk. Their approach has been named fictional realism. ${ }^{1}$ As I shall understand the notion, to be a realist, in broad brushstrokes, is to accept an ontological commitment to fictional

1. Prominent realists include David Braun (2005), Robert Howell (1979), Saul Kripke (2013), Nathan Salmon (1998; 2002), Stephen Schiffer (1996; 2003), Amie Thomasson (1999; 2003a; 2003b), Peter van Inwagen (1977; 1983; 1985; 2000; 2003).

Contact: Tatjana von Solodkoff <Tatjana.vonsolodkoff@ucd.ie> 
characters. For reasons that will hopefully become clearer in the course of this paper, I resist characterising fictional realism as the view that fictional characters exist. Maybe a less theoretically loaded way to express the realist commitment is this: It's to say that fictional characters are part of the 'furniture of the world' - to borrow a metaphor often used in this context. (There is, of course, considerable disagreement about how to cash this metaphor out, with different philosophers doing so in different ways, but it should hopefully be enough to fix ideas at the initial stage of my inquiry.) Fictional realism may seem like a somewhat exotic view at first, but it has gained many adherents. What seems particularly attractive about this approach is that it allows its defenders to take many claims of common sense at face value: Hermione Granger is a fictional character, Sherlock Holmes was created by Arthur Conan Doyle, and some fictional characters are better known than others. People seem to think that these claims are straightforwardly true. And fictional realists agree.

The opposing, conservative view has been described as fictional anti-realism, and as I use the term, fictional anti-realism is the denial of fictional realism. ${ }^{2}$ Fictional anti-realism also seems to have a theoretical advantage over fictional realism: it gets away with a sparser ontology, that is, it assumes fewer entities as part of the furniture of the world. The realist and the anti-realist thus disagree about which alleged entities are part of the furniture of the world.

But I am greedy; I want to have my cake and eat it too. So, in this paper I am going to suggest a view about fictional characters that combines the aforementioned benefits of both fictional realism and fictional anti-realism. This approach allows us to take just as many sentences at face value as the fictional realist traditionally can, but it also enables us to keep our ontological commitments to a minimum, hence matching the fictional anti-realist's advantage. On the view I develop and defend, the central task we face is that of explaining facts concerning fictional characters, where the relevant notion of explanation is distinctively metaphysical in character. To use an increasingly popular term, facts about fictional characters are grounded in other facts. Accordingly, I am going to call my approach grounding anti-realism (about fictional characters). Grounding anti-realism emerges as the plausible thesis that truths about fictional entities can be completely explained in terms of the existence and features of other things. Unlike some other fictional anti-realist views, it is reconciliatory; it aims at reconciling what we usually say and think with a sparse ontology.

Behind the ontological dispute about fictional characters lies a methodological one that has all too often been left implicit. This dispute concerns the very

2. Prominent anti-realists include Stuart Brock (2002), Antony Eagle (2007), Gareth Evans (1982), Anthony Everett (2005; 2007), Mark Sainsbury (2009), and Kendall Walton (1990; 2000). 
nature of ontological inquiry: its subject matter, its aims, and its methodology. This paper aims to bring these methodological issues to the fore.

In Section 1, I draw attention to the fact that two of the most prominent fictional realists have different meta-ontological commitments, and I present an alternative approach. In Section 2, I will defend a novel version of fictional antirealism. And in Section 3, I consider what metaphysical inquiry into fictional characters might look like on my proposed view. Finally, in Section 4, I will try to explain why the approach I am presenting here should be considered an antirealism about fictional characters. I will also suggest that my approach to the ontological debate about fictional entities does not undermine the enterprise of metaphysics of fictional characters.

\section{I.}

Talk about fictional characters is varied and heterogeneous. We can talk about the content of fictions, for example, "Hermione is very clever", we can engage in more informed talk about characters, call it external talk, for example, "some fictional characters are better described than others", or we can ascribe feelings towards them, such as "I pity Anna Karenina".

Fictional creationists take appearances at face value: they claim that fictional characters are abstract objects, literally created by authors, and are thereforesince the author might have failed to exist or might have decided to write a different story - contingently existing entities. Creationists have a much easier time than those with rival views in accounting for claims that common sense seemingly takes to be true, and that's particularly the case when it comes to external talk. Both Peter van Inwagen and Amie Thomasson - the two most vocal defenders of creationism - acclaim their respective accounts as offering the best account of our ordinary talk and thought about fictional characters. ${ }^{3}$ And, indeed, Thomasson, for example, tells us that her defence of her theory is "based largely on its ability to better preserve central elements of the common conception of fictional characters embodied in our literary practices" (2003a: 139) and van Inwagen makes similar remarks. ${ }^{4}$ Creationism, then, emerges as the least revisionary amongst rival metaphysical views of fictional characters.

Note that the way I spelled out creationism says nothing about whether fictional characters are part of the furniture of the world. The view holds that fictional characters exist, but this itself does not entail that we are ontologically committed to them. That claim requires additional assumptions. As for Thom-

3. See von Solodkoff and Woodward (2018) for worries about van Inwagen's creationist.

4. See van Inwagen (1977: 304-307) and Hanley (2003: esp. 126-128) for discussion. 
asson and van Inwagen, they both accept that we have an ontological commitment to Hermione and Holmes. But there is a fact that's often neglected in the literature: van Inwagen and Thomasson approach the question of whether fictional characters exist from two very different methodological points of view. 5 So even if they agree on the answer to the first-order ontological question - are there fictional characters? - they disagree on the answer to the second-order meta-ontological question of how we should go about answering the firstorder question.

van Inwagen, for instance, thinks of himself as an arch-Quinean. Drawing on Quine's answer to what he considered the ontological question - what exists? van Inwagen presents us with an argument to the effect that we ought to accept an ontological commitment to fictional characters. As a Quinean, van Inwagen thinks that looking at our best theories of the world is also our best guide to finding out what to accept into our ontology and, hence, we ought to find out what entities these privileged theories quantify over. And if it turns out that the theories quantify over the entities indispensably - the theories cannot be paraphrased and we refuse to adopt a fictionalist ${ }^{6}$ position - then we ought to embrace ontological commitment to these entities.7 But unlike Quine himself, van Inwagen believes that when we write down our best total theory of the world, we will find ourselves quantifying over fictional characters and we do so indispensably. And this is because our best total theory will include our best literary theory, a discipline including "all 'informed' discourse about the nature, content and value of literary works" (van Inwagen 1977: 302).

Thomasson's approach to ontology, however, isn't Quinean in character, and so van Inwagen will think that Thomasson's route to realism is suspect even if it has managed to get her to the right destination. Thomasson (2007) thinks that ontological questions are so easy that they don't deserve substantive philosophical debates. By using conceptual analysis and some empirical enquiry, she argues, we can resolve questions of the form "do Fs exist?" in a straightforward way. Thus, it seems as clear to her that there are fictional characters as there are marriages and contracts. (For what it's worth, I don't agree with Thomasson that the question "do fictional characters exist?" is easily answered. If, for example, we could semantically reduce all talk about fictional characters to talk that is free of such entities then this may be a good reason to deny their existence. On

5. Mary Beth Willard (2013) has an interesting discussion of how methodological issues come to bear on the debate over fictional characters.

6. I have in mind the fictionalist view Hartry Field (1980) developed towards mathematical talk in Science without Numbers. Note that the kind of fictionalism Field advocates is different in important ways from the kind of pretense-theoretic fictionalisms defended by, e.g., Walton (1990).

7. The argument was first given in van Inwagen (1977); it gets restated in various ways in van Inwagen (1983; 1985; 2000; 2003). 
Thomasson's easy ontology view, however, the paraphrasing strategy is of no interest.) And just to be clear: Thomasson (2003a: 152) explicitly characterises her approach to the debate about fictional entities in contrast to the orthodox Quinean setting. So we shouldn't lose sight of the fact that their respective approaches to what is perhaps the most central meta-ontological question, namely, how we ought to approach ontological disputes, differ quite radically.

Now, a growing number of philosophers have sought to find room for an approach to ontology that stands opposed to Quineanism (and it also stands opposed to Thomasson's easy ontology). This ontological approach pays special attention to how some facts or entities are related to other facts and entities, and defenders of the approach make use of the technical notions of grounding or metaphysical explanation, to name just two. ${ }^{8}$

The central idea, that I want to make use of in this article, is that there is a way of explaining that is distinctively metaphysical in character. And this subsequently opens up the possibility that even if talk of fictional characters cannot be paraphrased away (a strategy Quineans often hope to successfully apply, but that seems rather hopeless in the case of fictional talk), we might still be able to show that facts about such things can be metaphysically explained by facts about other things. While we might have to forgo semantic reduction, the availability of metaphysical reduction remains. ${ }^{9}$ And just as the central goal of semantic reduction is to show that we can afford a sparser ontology, the central goal of metaphysical reduction is to show that we only need to accept an ontological commitment to the entities involved in the reduced facts.

Let us call the theorist I have in mind here a grounding theorist. A grounding theorist will think that there are some facts that ground other facts but are themselves ungrounded. And she thinks that a central task of ontological inquiry is to figure out what these ungrounded facts are and how they ground the grounded facts. The grounding theorist I have in mind will also hold that questions of ontological commitment ought to be questions about what is ungrounded. And the ungrounded entities are the ones featured in the ungrounded facts. She will think that one of her tasks as an ontologist is to show how facts featuring grounded entities can be metaphysically explained by facts that only refer to and quantify over ungrounded entities. My grounding theorist will further think that parsimony amongst the ungrounded entities is a theoretical virtue and that, other things being equal, a theory with fewer ungrounded entities is preferable to one with more ungrounded things. (The grounding-theoretical view I've just described is not the only meta-ontological view that makes use of the notion of

8. The prominence of this approach is usually traced to the influence of Kit Fine $(2001 ; 2005$; 2009). Ross Cameron (2010), Cian Dorr (2005), Joseph Melia (2005), Jonathan Schaffer (2009), Ted Sider (2009; 2011), and Robbie Williams (2010), to name just a few, defend related views.

9. For more on paraphrase strategies in metaphysics see von Solodkoff (2014b). 
grounding. I will distinguish it from other grounding views in the last section of this article.)

Recall what I wrote in the introduction: a fictional anti-realist is someone who denies that we are ontologically committed to fictional characters, that Holmes and Hermione are not part of 'the furniture of the world'. Nothing I have described so far implies that the grounding theorist is a fictional anti-realist. After all, she might arrive at the conclusion that facts about fictional characters cannot be metaphysically explained by kosher facts. But I think they can, so I am going to defend a view which I call fictional grounding anti-realism (I will omit the 'fictional' in what follows). And in the next section I'm hoping to show how the grounding anti-realist can deploy the notion of grounding within the context of her own account.

\section{2.}

Being a fictional anti-realist means answering the first order question-are fictional characters part of the furniture of the world? - in the negative. The fictional anti-realist I am contemplating in this section is not a Quinean but a grounding theorist, and, therefore, her answer to the second order question - how should we conduct ontological disputes? - differs from that of the Quinean. ${ }^{10}$

She thinks that what we need to do in order to answer the first order question is to see whether fictional characters are referred to or quantified over in the grounding facts. And if they aren't then she takes this as a definite reason to deny that we are ontologically committed to fictional characters.

With the idea of grounding in place, the goal of this section is to show how facts about fictional characters can be explained by appeal to facts which don't refer to or quantify over such things. This will be sufficient to show that we are not ontologically committed to Holmes and his ilk. ${ }^{11}$ Before we start with offering explanations for particular facts about fictional characters, let me introduce four principles that will guide us. ${ }^{12}$ One of the key advantages of being a grounding theorist is that it allows her to reconcile how we usually think and

10. But see von Solodkoff and Woodward (2013) for why the typical grounding theorist should not be considered an anti-Quinean.

11. One final note before we get started: although I am engaging in fact-talk, I view this as being ontologically harmless. I'm assuming that Kit Fine is correct when he writes that "we might express statements of ground in the form ' $S$ because $T, U \ldots$.', as long as the 'because' is taken in a suitably strong sense, and thereby avoid all reference to propositions or facts or to the concept of truth" (2001: 16). Nothing I am saying here should hinge on whether we accept an ontology of facts or not.

12. I've adapted these principles from von Solodkoff (2012). 
talk with her preferred ontology. And hence, the grounding theorist who is also a fictional anti-realist will subscribe to the principle of modesty:

(MODESTY) Many ordinary claims about fictional characters are true.

Our grounding anti-realist believes that she can explain various facts about fictional characters in terms of facts about other things (i.e., not fictional characters). Thus she holds:

(EXPLANATION) True claims about fictional characters can be fully metaphysically explained solely by the existence and properties of other entities.

And a consequence of this is:

(GROUNDING) The grounding facts do not involve fictional characters.

Since this grounding theorist believes that we are only ontologically committed to ungrounded entities (i.e., those referred to and quantified over in the ungrounded facts) and because (GROUNDING), it follows:

(SPARSITY) We are not ontologically committed to fictional characters.

I am going to assume that (MODESTY) is uncontroversial. In this article I attempt to show how someone who embraces the grounding-theoretic view I described in the last section can be a fictional anti-realist. Since the grounding theorist thinks we are only ontologically committed to fictional characters if facts about them cannot be grounded in other facts, my task in this section is to show that (EXPLANATION) and, hence, (GROUNDING) are true. That is, facts about fictional characters can indeed be grounded in facts that do not refer to or quantify over fictional characters. For if they can, (SPARSITY) holds, and we are not ontologically committed to Holmes and Hermione.

Now, it is obviously beyond the scope of this paper to give explanations for each and every truth about fictional characters. Indeed, it makes sense to focus on examples from external talk. The rationale for focusing on these cases is that they are the ones that have been thought to motivate fictional realism, since they resist paraphrasing. Very roughly what distinguishes external from internal talk 
about fictional characters is that it seems that the latter can be reinterpreted with the help of a story operator. Consider "Hermione is Harry's friend" or "Holmes plays the violin". It seems fair to both sentences to understand them as being implicitly prefixed with an operator of the form 'according to the fiction $\mathrm{f}^{\prime}$. Thus, "Hermione is Harry's friend" can be paraphrased as "according to the Harry Potter canon, Hermione is Harry's friend". Such a paraphrase renders the claim ontologically innocent regarding fictional characters, since the existential impact is now explicitly located within the fiction, not the real world.

But the same strategy cannot be applied to external talk about fictional characters. External sentences always require the interpreter to step outside the world of a single fiction. Paradigmatic examples of such sentences are claims that seem to quantify explicitly over fictional characters such as "there are fictional characters", but also attributions of literary properties, for example, "Hermione Granger is a fictional character", "Holmes was created by Doyle", or "Holmes is a fictional detective" (the latter sentence seems to stand with one foot outside and the other foot inside the fictional world). Other paradigmatic external sentences are transfictional claims with which we compare two or more fictions, such as "Holmes is taller than Frodo", or "Holmes appears in more than one story". Still other external claims relate a fictional character to the audience of the fiction it originates from, for example, "Holmes is famous", but also "Holmes is more famous than any real detective". Since the story operator strategy can only be applied to claims that concern the content of a single fiction, none of the above examples of external talk can be paraphrased using this strategy, and it is unclear what alternative systematic paraphrastic treatment can be given to them. They seem to genuinely resist paraphrasing into ontologically innocent sentences. But as we will see, they don't resist metaphysical explanation. And if our anti-realist can show how the sample cases can be explained without the help of fictional entities then it looks as though an ontological commitment to fictional characters may well be undermotivated.

Let me point out that I'm not married to the sample explanations I am about to offer. Two grounding anti-realists could well disagree about what grounds facts about fictional entities and, hence, they could disagree about which entities figure in the facts that do the explaining. Thus one of them might argue that what grounds facts about fictional entities are facts about the interpretations of fictions. (This is essentially the view Ross Cameron suggests in Cameron 2013.) But given the attractiveness of fictional creationism, a natural proposal emerges, one which identifies the grounds in terms of what authors do when they produce fictions and how the audience responds. Thus, my proposed metaphysical explanations will refer to and quantify over authors and other concrete things in the explanans. Since the explanans of the metaphysical explanations are meant to be ungrounded facts, my sample explanations suggest that we are ontologi- 
cally committed to composite objects. But my focus in this article is not on showing what entities we are ontologically committed to, but rather on showing that we are not ontologically committed to fictional characters. And if facts about fictional characters can be fully explained by facts about concrete entities (as I think they can), I take this as a reason to deny ontological commitment to Holmes and Hermione. It will prove to be useful to distinguish between intermediate metaphysical explanations and ultimate metaphysical explanations. If you don't like composite objects, think of the explanations to follow as intermediate metaphysical explanations, taking you one significant step closer to ultimate metaphysical explanations. In what follows, I will usually omit talk of 'intermediate' and 'ultimate', but I hope it will be clear from context when I am thinking of a particular metaphysical explanation as being an intermediate one.

So what could the explanations of facts concerning fictional characters in terms of authors, their actions, and audiences look like? Let's start with a simple common-sense truth: there are fictional characters. My strategy, as I intimated above, is to look to what creationists have typically said about such cases and piggy-back my grounding-theoretic explanations on these creationist ideas. Thus, for example, Thomasson suggests that (merely) fictional characters exist because authors use names (or descriptions) in certain ways when producing fictions. She writes, ${ }^{13}$

Just as marriages, contracts, and promises may be created through the performance of linguistic acts that represent them as existing, a fictional character is created by being represented in a work of literature. If there is no preexistent object to whom Austen was referring in writing the words above, writing those words brings into existence the object therein described: The fictional character Emma Woodhouse. (Thomasson 1999: 13)

According to Thomasson, authors perform illocutionary acts typical for writing fiction that bring it about that a fictional character exists. We may still ask what exactly these illocutionary acts are and what the fictional names and descriptions used in them refer to. One plausible answer seems to me to say that when Doyle introduced the name 'Holmes' he was pretending to refer to a real person. ${ }^{14}$

Let's say that in using the name 'Holmes' in this pretend way Doyle was act-

13. Thanks to an anonymous referee for this journal for drawing my attention to this passage.

14. An anonymous referee suggested that it seems more plausible that Doyle was referring to a fictional character when creating Holmes than that Doyle was pretending to refer to a real person. I don't take a stance here on how to best interpret the fiction-creating process, but at least the view that Doyle was pretending to refer seems to me to be a viable position. 
ing in a quasi-referential manner. ${ }^{15}$ Thus, when faced with the question of what grounds the fact that there are fictional characters, we'll explain:

(1) There are fictional characters because authors use names/descriptions in a quasi-referential manner when engaging in fiction-writing, pretending to refer to or describe real things.

Note that the explanans of (I) does not refer to or quantify over fictional characters, which means we can metaphysically explain the fact that there are fictional characters without mention of such entities.

An alternative proposal of how to metaphysically explain the fact that there are fictional characters may be derived from the following thought. Mark Sainsbury (2010: 150), in discussing this sentence, offers "there are fictions according to which there are characters" as a way of paraphrasing the claim that there are fictional characters. If a reality that contains abstract objects, which fictions probably are, doesn't offend your taste for desert landscapes, then you might accept this as a metaphysical explanation for the truth that there are fictional characters: it's true, because there are fictions according to which there are characters. Remember that my aim here isn't to defend my explanations as being the only explanations that are available, just to establish the availability of some explanation that delivers what the anti-realist was after.

From the explanation of the basic fact that there are fictional characters we can now build up to more complex cases. To begin, note that some fictions feature real life people, for example, Napoleon. ${ }^{16}$ This in turn gives rise to the distinction between fictional characters and merely fictional characters: Napoleon and Holmes might both be fictional characters, but only Holmes is merely fictional. Our earlier explanation covers the general case, but it's easy to extend it to cover the more specific one:

(2) There are merely fictional characters because authors use names/ descriptions in a purely quasi-referential manner when engaging in fiction-writing.

Roughly, an act of pretend reference is purely quasi-referential if the corresponding act of reference would have resulted in reference failure. The idea is that if no one had quasi-referred using the name 'Holmes', then Holmes would have not existed. Whereas if no one had quasi-referred using 'Napoleon', the emperor of

15. I borrow the term 'quasi-reference' from Schnieder and von Solodkoff (2009), see also Moltmann (2015).

16. This is controversial: van Inwagen denies that the Napoleon of War and Peace is the real Napoleon (1977). But see Friend (2000). 
the French, would have existed nonetheless. That is the intuitive sense in which merely fictional characters can be said to depend upon the activities of authors, whereas 'real' fictional characters like Napoleon don't.

From the explanation of the quantificational fact that there are fictional characters, we can also obtain explanations for particular instances. What explains why Holmes is a fictional character? The natural candidate is (3):

(3) Holmes is a fictional character because an author used the name 'Holmes' in a quasi-referential way when engaging in fiction-writing.

Moreover, our anti-realist will ground the fact that the fictional character Holmes exists in exactly the same way: the fictional character Holmes exists because an author used the name 'Holmes' in a quasi-referential way when engaging in fictional writing.

And notice that even if other authors - writers of fan fiction, say-use the name 'Holmes' in a quasi-referential way, it was Doyle who first used the name 'Holmes' in this manner. This naturally suggests the following explanation that Holmes was created by Doyle:

(4) Holmes was created by Doyle because Doyle was the first author to use the name 'Holmes' in a quasi-referential way when engaging in fictional writing.

This will need some refining, because someone else might have used the name 'Holmes' when engaging in fiction-writing. What that would show is that there were two characters who shared a name. This would force us to distinguish two characters, Holmesi and Holmes2, and thereby distinguish two names, 'Holmesi' and 'Holmesz'. The point would then be that Doyle was the one who first used the name 'Holmesz' when engaging in fiction-writing. ${ }^{17}$

Though we've only considered relatively simple external truths about fictional characters so far, this is still significant: if these explanations are granted, we've shown how truths about fictional characters can be explained without mention of such things. Nonetheless, our explanatory project is still in baby shoes and trickier cases lie ahead. Consider, for instance, truths expressed by impure external sentences, such as the claim that Holmes is not only a fictional character, but a fictional detective. In this case, the fact that 'Holmes' was used by an author in a quasi-referential way isn't sufficient to explain why Holmes is

17. For more discussion of this and some problems that arise when it comes to giving a criterion of creation of fictional entities, see Brock (2010). Nothing I've said here is rendered problematic by Brock's objections to creationism. 
a fictional detective. But the following explanation, which builds on (3), seems acceptable, at least as an intermediate explanation:

(5) Holmes is a fictional detective because an author used 'Holmes' in a quasi-referential way when engaging in fiction-writing, and it's fictional that Holmes is a detective.

Though we've used the name 'Holmes' in the explanation, notice that we've done so within the scope of 'it's fictional that' and I shall assume that there is an acceptable way to ground facts about what is fictionally the case. A satisfying explanation would, I suppose, say something about what makes it fictional that the name 'Holmes' refers to a detective or what makes it fictional that the name 'Hermione' refers to a wizard. There has been a lot of discussion of how to understand truth in fiction. ${ }^{18} \mathrm{I}$ hope I can remain neutral on the right account here, but I will point in a direction: That Holmes is a detective seems to me to be best explained in terms of there being a prescription to imagine that Holmes is a detective. This is essentially Ken Walton's proposal of how to understand claims about the content of a fiction. ${ }^{19}$ Yet, Walton also thinks that fictional characters don't exist and a standard problem for his account is that he can't appeal to the proposition that Holmes is a detective. He doesn't believe that there is such a proposition, since 'Holmes' fails to refer (and is hence meaningless). But without a proposition being expressed by 'Holmes is a detective' it's difficult to see how you and I can agree on this claim. Successful communication about fiction and fictional characters requires propositions, it would seem. Walton explains this success in terms of shared (and often authorised) games of make-believe, but it makes for a more complicated explanation of our communication. My approach is simpler insofar as it holds that there is the proposition that Holmes is a detective. It's just that its existence is grounded in something else, that is, the pretenseful use of the name 'Holmes'.

A popular pastime when engaging in talk about fiction is to draw comparisons between characters from different fictions. Consider the fact that Holmes is taller than Frodo. We already know how to explain the existence of the relata, so what remains to be explained is just the fact that Holmes stands in the taller-than relation to Frodo. And it is clear that this has something to do with the contents of their home fictions. Why do we take it to be true that Holmes is taller than Frodo? Here's a plausible explanation:

18. For classic discussions of fictional truth, see Lewis (1978) and Walton (1990). For an overview of the debate, see Woodward (2011).

19. See Walton (1990). 
(6) Holmes is taller than Frodo because an author used 'Holmes' in a quasi- referential way when engaging in fictional writing and it's fictional that Holmes is at least normal in size by actual human standards and an author used the name 'Frodo' in a quasi-referential way when engaging in fictional writing and it's fictional that Frodo is small in size by actual human standards.

Transfictional comparison is, hence, explained by referring to the fictions individually without relating the fiction or their characters directly to one another. We cannot compare the fictional characters to one another in the explanans, since this would conflict with (GROUNDING). Recall that our task is to show that facts about fictional characters can be metaphysically explained with facts that neither refer to nor quantify over fictional entities. So, we have to explain the fact that Holmes is taller than Frodo without referring to them. (Why 'actual human standards'? A fiction might well say that five metres is small by human standards, but we are talking about what we in our world take to be tall or small for a human.)

Let us turn to cases that relate a fictional character to the audience of the fiction from which it originates, for example, "Holmes is a famous fictional detective" and "Holmes is more famous than any real detective". What grounds the fact that Holmes is famous? Mark Sainsbury hints at one answer to this when he tells us that we must take into account "the fact that for something to be famous is (and nothing more than) for it to be thought about in the right sort of way" (2009: 137-138). This seems not quite right to me. Even if lots of people think about God in the right sort of way, it sounds wrong to my ear to say "God is famous" purely because of that. It seems more natural to hold that for NN to be famous (in a community) is for lots of people in that community to know about NN. So a first explanatory idea would be that Holmes is famous because lots of people know about (the fictional character) Holmes. The question now becomes: what grounds the fact that lots of people know about Holmes? Sainsbury (2009: 136) himself advocates a propositional reduction of "thinking about" which extends naturally to "knowing about". ${ }^{20}$ The thought here would be that the fact that lots of people know about Holmes is reducible to the fact that lots of people know that Holmes is $F$, for some predicate ' $F$ '. But I stress that the kind of propositional reductions I have in mind are neither syntactical, semantical nor conceptual reductions. They are metaphysical reductions, claims about what grounds what. Sainsbury, by contrast, seems to think of propositionalism as giving a semantic reduction and thereby leaves himself open to the charge that such

20. See also Sainsbury (2010). 
a semantic reduction doesn't fit the linguistic data. ${ }^{21}$ Those arguments don't, I think, work against the propositionalist reductions I am appealing to since I am doing metaphysics, not semantics. ${ }^{22}$

Now, it's conceivable that the relevant value of ' $F$ ' might vary: perhaps Mayim knows that Holmes is a fictional detective, whereas Juan knows that Holmes is a fictional man, for instance. But it seems clear that, as a matter of fact, it's widely known that Holmes is a fictional character. So this suggests the following intermediate explanation:

(7?)Holmes is famous because lots of people know that Holmes is a fictional character.

As far as it goes, this seems plausible. Hang on-couldn't Holmes be famous even in a scenario where we had made a massive mistake and mistaken the Holmes-stories for non-fictional reports of real events? Maybe, but what's responsible for the truth of a claim isn't the same as what's required of reality for that claim to be true. (Compare: $p$ grounds the truth of $p$ or $q$ but the truth of ( $p$ or q) doesn't require the truth of p.) Questions of ground, as I understand them here, are questions of responsibility rather than requirement. ${ }^{23}$

But the explanation still talks about Holmes. What we need to show is that the fact that Holmes is famous can be explained without referring to the fictional character. So though ( 7 ?) is a step in the right direction, the anti-realist needs to specify what grounds the fact that lots of people know that Holmes is a fictional character. And I think the following makes sense:

(7) Holmes is famous because lots of people know that it's fictional that Holmes exists.

Bear in mind that I do not claim that the explanation specifies anything as to 'what speakers mean' when they say that Holmes is famous. I claim only that Holmes' fame is grounded in the fact that it's fictional that Holmes exists. And though the explanans of (7) features the name 'Holmes', it does so safely embedded within the fictional operator. And as with (5), I shall assume that there is a plausible way to ground truths about fictions without reference to fictional characters.

A more complicated example of a similar sort is provided by the fact that

21. Zoltán Szabo (2003) and Graeme Forbes (2006) criticise propositionalism. See also Crane (2008) for a discussion of Sainsbury's conception of 'thinking about' and its evolution.

22. For a discussion of the relationship between semantic theorising and grounding-theoretic (or 'fundamentalist') metaphysics, see von Solodkoff \& Woodward (2013).

23. I discuss this further in von Solodkoff (2012). 
Holmes is more famous than any real detective (Howell 1979). What grounds this fact? Well, this looks like a step in the right direction: Holmes is more famous than any real detective because Holmes is more famous than G. S. Dougherty and Holmes is more famous than J. McLevy, and Holmes is more famous than ... (continue in this way, for each real detective). This follows from a standard account of how universal generalisations are grounded, namely in their instances. So what the anti-realist now needs to show is that each individual conjunct is grounded, that is, that Holmes is more famous than Dougherty, and that Holmes is more famous than McLevy, and so on. And it's easy to see how this will go: we'll say that Holmes is more famous than McLevy because more people know about Holmes than know about McLevy, that is, because more people know that Holmes is $F$, for some predicate ' $F$ ', than know that McLevy is $G$, for some predicate ' $G$ '. And it is true, after all, that there is no fact about McLevy that is more widely known than the fact that it's fictional that Holmes is a detective. The explanation then looks like this:

(8) Holmes is more famous than any real detective because more people know that it's fictional that Holmes is a detective than know that G. $S$. Dougherty is $F$ (for any predicate ' $F$ ') and more people know that it's fictional that Holmes is a detective than know that J. McLevy is $G$ (for any predicate ' $G$ '), and more people know that ... (continue in this way, for each real detective).

Perhaps I was too quick in calling this an explanation. Of course, it's rather the sketch of what an explanation would look like, were I able to list every real detective. Surely this could be done, but I would understand if nobody is very interested in doing that. But this only means that no one is very interested in knowing the metaphysical grounds of the fact that Holmes is more famous than any real detective. If that leaves a faint feeling of dissatisfaction still, I urge you to remember that what we're up to when giving the specific explanations that give us the metaphysical grounds of facts is very different from offering paraphrases or stating what has been said by the speaker even broadly construed. In particular, the constraints on the semantic project are much stricter than on the metaphysical project. Part of what makes paraphrasing difficult, as Stephen Yablo points out, are the "requirements of a finitely based notation" (2005: 95). While paraphrases need to be finite and recursively specified, no such constraints limit metaphysical explanations.

I shall consider two examples, "Holmes appears in more than one story" and "Snowy is a fictional character". What both sentences have in common is that, if true, they seem to require the co-ordination of usages of fictional names.

Consider first the fact that Holmes appears in more than one story. Drawing 
on the explanation of why Holmes is a fictional character, you might initially think the following is a good candidate:

(9?)Holmes appears in more than one story because an author used the name 'Holmes' in a quasi-referential way when engaging in fictional writing and an author used the name 'Holmes' in a quasi-referential way when engaging in fictional writing, the first act of fictional writing isn't identical to the second.

But this won't do, as it doesn't establish that the two fictional characters are identical, only that two characters from two different fictions share a name. To solve this problem, I'd like to make use of the idea that two distinct referential acts can be coordinated. ${ }^{24}$ The idea here is, I hope, intuitive: when Doyle used the name 'Holmes' when writing a later story, his use was linked to and in some sense dependent upon, his earlier quasi-referential use of that same name. This generates the following explanation of the fact that Holmes appears in more than one story:

(9) Holmes appears in more than one story because an author used the name 'Holmes' when engaging in fiction-writing and an author used the name 'Holmes' when engaging in fiction-writing and the quasireferential acts are coordinated, and the first act of fiction-writing isn't identical to the second.

Possibly, a better explanation would be phrased in terms of the facts in virtue of which the two quasi-referential acts are co-ordinated. But at least as it stands, the explanation seems to be adequate for the needs of our grounding anti-realist who attempts to show that the facts that require explanation in (9) can be explained by a fact that does not talk about Holmes anymore.

Sometimes when a fiction is translated into another language some of its characters are named differently from how the author named them. In the French-language original of The Adventures of Tintin, Tintin's small dog is called 'Milou', but in the English translation he is referred to as 'Snowy'. Now, while we would agree that Snowy is a fictional character, this is not because the author, the Belgian Hergé, used 'Snowy' in a quasi-referential way; he used 'Milou'. So when the translator used 'Snowy' when translating the story, her use was linked to and in some sense dependent upon, Hergé's earlier quasi-referential use of that same name. The explanation for why Snowy is a fictional character might then look something like this:

24. This idea has been emphasised by Friederike Moltmann (2013). 
(10) Snowy is a fictional character because an author used the name 'Milou' in a quasi-referential way when engaging in fictional writing and a translator used the name 'Snowy' when engaging in translation and the quasi-referential acts are co-ordinated.

(As for a more detailed account of how to understand co-ordinated uses of fictional names, I defer to Fiora Salis's 2013 discussion on the matter.)

Let us finish the project of giving metaphysical explanations for talk about fictional characters with a notoriously challenging kind of talk: negative existentials. Claims such as "Hermione doesn't exist" are tricky for everyone; they simply don't seem to allow for a literal interpretation. If you are a theorist who denies that fictional characters exist, you are facing the issue of what 'Hermione' refers to or how else to interpret the sentence. And if you accept the existence of fictional characters (e.g., as abstract objects) interpreting such claims poses even more of a challenge. In a different article (2014a) I argue that negative existentials should be interpreted as claims about the objects, for example, Holmes or Hermione, but the point of such claims is only seemingly to negate their existence. Rather, such claims negate that the objects in question belong to a particular kind. My view is inspired by Thomasson's observation that "statements like 'there is no Lear' [are] quite naturally interpretable as [claiming] that ... 'there is no (real) person who is Lear'" (1999: 112). This is a step in the right direction, but it isn't quite far enough. When an ordinary speaker claims that Lear doesn't exist, it's natural to think that she is not only ruling out that Lear is a real man; she seems to rule out that he isn't a real human or a real animal or a real mineral either. (Lear is, however, a real fictional character, a real pretend object and a real abstract entity.) To account for this all-around denial, rather than tying the candidate kind in question to the kinds that a fictional characters belongs to in the fiction, I propose that everyday negative existentials ought to be interpreted by means of the kinds non-pretend object (as opposed to pretend object) and concrete object. The emerging proposal is:

"n doesn't exist" is true in a context $\mathrm{c}$ iff $\mathrm{n}$ isn't a $\mathrm{Kc}$,

where ' $K$ ' is 'non-pretend object' or 'concrete object', depending on the context. ${ }^{25}$

25. For a detailed account of the circumstances in which ' $K$ ' takes the value 'non-pretend object' rather than 'concrete object' and vice versa, see von Solodkoff (2014a). 
Now, consider the sentence "Hermione doesn't exist". According to the here-presented view of how to treat negative existentials, the sentence is true because Hermione isn't a non-pretend object. Or, deleting the double-negation, because she's a pretend object. Arguably, not every pretend object is a fictional character (your imaginary childhood friend is the former but not the latter), but in Hermione's case she is correctly described as a pretend object because she is a fictional character. This suggests that the same fact that metaphysically explains why Hermione is a fictional character is also suitable to explain why Hermione is a pretend object: it's because an author used the name 'Hermione' in a quasireferential way when engaging in fiction-writing. Thus, we can metaphysically explain the negative existential in this way:

(11) Hermione doesn't exist because an author used the name 'Herm-

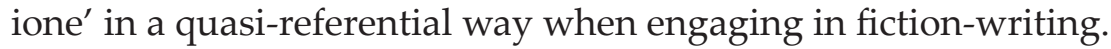

(I discuss different varieties of negative existentials in my 2014a. Once negative existentials are interpreted according to my proposal, explanations for these interpretations are easily modelled on the explanations offered in this article.)

The explanatory project facing our anti-realist is far from complete. But I hope that the idea has become sufficiently clear. As an anti-realist who rejects the idea that fictional characters are amongst the furniture of the world, I seek to explain facts concerning fictional entities in terms of facts concerning other things. But the explanations that I think need to be given are not semantical ones-the goal is not to paraphrase away talk of fictional characters, at least in the way that Quineans conceived of that project-but rather to offer specifications of which facts ground facts about fictional characters. And though this project might result in long and messy explanations and lack the systematicity desired for paraphrases, I claim that this is acceptable, since we have no guarantee that our 'grounding story' will be systematic and neat. But note that while the explanations I have given here lack the systematicity of paraphrases, there are nonetheless patterns that emerge; similar claims will be similarly grounded. The starting point will always be authors and their activities qua authors.

I also concede that though I have given explanations for a range of facts concerning fictional characters, I certainly haven't shown that all facts concerning fictional characters can be explained even metaphysically in an adequate fashion. You might, for instance, point to claims concerning the intentional attitudes we apparently bear to fictional characters: Mayim admires Hermione, Kai is jealous of Holmes, Juan fears Cthulhu. But I emphasise that though the range of cases I've covered is far from complete, it's still quite extensive. Finally, I also think that caution is merited. Exactly how we should understand intentional attitude ascriptions like 'Mayim admires Hermione' is a notoriously vexed question, 
and generates a number of difficult puzzles for everyone, be they realists or not. Whatever the best account of intentional attitude ascriptions is, I am optimistic that the here-described anti-realist grounding view can piggyback on it and use it in the grounding explanations. Rather than commit myself to some specific approach to such cases, I hope it's legitimate in the context of this paper for me to remain neutral here and rest content with showing that a significant range of problematic cases can be explained within the context of an anti-realist approach within a grounding-theoretic setting to the debate about fictional entities.

\section{3.}

In the previous section I attempted to show that facts about fictional characters can be metaphysically explained by facts about authors, their actions, and the audience. I took this to mean that we can avoid an ontological commitment to fictional characters and that, consequently, I am defending an anti-realism about fictional characters. But this needs a bit more explaining, which I attempt to do in this section. Further, I want to make sure that I have not given you a wrong impression, namely, that I am suggesting that when engaging in the metaphysics of fictional characters, all we need to do is figure out whether fictional characters are grounded or not. And while it's certainly in the realm of logical possibility to hold that facts about fictional characters cannot be metaphysically explained by any kosher facts, such a view is exotic, and I assume very few would flirt with it. But I don't think that there are no metaphysically deep questions concerning fictional characters other than whether they exist and, if they do, how they are grounded. So, in this section, I'd also like to dispel the worry that my view does not leave room for a metaphysics of fictional characters. I'll start with the latter.

The worry that the grounding theorist cannot accommodate a metaphysics of fictional characters has a predecessor in feminist metaphysics: Elizabeth Barnes (2014) points out that the focus on grounding in contemporary metaphysics seems to rule out the prospect of feminist metaphysics. ${ }^{26}$ After all, most, maybe all, feminist metaphysicians would agree that gender is not ungrounded. ${ }^{27}$ It seems that there are two central, related concerns: First, there is the question of whether a grounding framework allows for feminist metaphysics, or social metaphysics more generally, if the focus of this framework is entirely on the fundamental. And second, there is the question of whether ontological inquiry through the help of grounding renders all existence questions easy or even trivial. If so, this would seriously limit the possibility of social ontology as

26. See also Mikkola (2016).

27. But see Sider (2017) for how someone might argue for the ungroundedness of gender. 
a discipline. In fact, it would make it pointless, once you ruled out that there are social entities amongst the ungrounded. I take it we agree that this would be an unacceptable result.

What holds for feminist metaphysics equally applies to the metaphysics of fictional characters. If grounding theorists hold that metaphysics is only about the ungrounded entities then the metaphysician of fictional characters is out of her job once she has determined that fictional entities are grounded. Similarly, if existence questions are easy or even trivial, then this leaves no room for an ontology of fictional characters, once fictional characters as ungrounded entities are ruled out. But I will point to reasons for thinking that the existence question isn't easy.

In reply to these worries, Jonathan Schaffer (2017) and Ted Sider (2017) argue, persuasively to my mind, that there are many questions in feminist metaphysics that are metaphysically deep and interesting, and that their importance can be accommodated in a framework that distinguishes between grounded and ungrounded entities. ${ }^{28}$ They would hold the same, I assume, about metaphysical questions concerning fictional characters. Such questions would include whether fictional characters are created by their authors, whether fictional entities are abstract, and how we can make sense of not-merely fictional characters immigrating into fictional works. And we should, presumably, also include a richer account of our talk and thought about Holmes and his ilk in a complete metaphysical theory of fictional characters. And that's because we don't just want to know what is metaphysically responsible for the truth of a claim, we also want to know why the sentence is true. Doing so requires the grounding theorist to give full explanations that combine the metaphysical and the semantic (cf. Williams 2010; von Solodkoff 2012). To give you an idea of what a full explanation would look like consider "Holmes has been created by Doyle". By drawing on creationist resources, we can give the following full explanation:

"Holmes has been created by Doyle" is true because Holmes has been created by Doyle and, in reality, Doyle used 'Holmes' in a quasi-referential way when engaging in fiction-writing for the first time.

This full explanation is acceptable to the grounding anti-realist, since the metaphysical part that is within the scope of the 'in reality'-operator does not mention fictional characters.

If we think the subject matter of ontology should include what exists as well as what grounds what, then a further question suggests itself: how do we go

28. For a very interesting and well-developed account of how to use a grounding framework within social ontology more generally see Epstein (2015). 
about figuring out what groundedly exists? Schaffer suggests that we should be rather permissive about what exists. (He has an ally here in Thomasson 2007, but Thomasson doesn't share his commitment to grounding.) He holds that "contemporary existence debates are trivial, in that the entities in question obviously exist" (2009: 357, original emphasis). ${ }^{29}$ If he is right about this, then any disagreement about whether fictional characters exist or not must be misguided. In fact, Schaffer takes an explicit stance on the existence of fictional characters and writes:

As to the debate over fictional characters, here is a proof of the existence of a particular fictional character:

[(P)] Arthur Conan Doyle created Sherlock Holmes.

[(C)] Therefore Sherlock Holmes exists.

$[(\mathrm{P})]$ is a literary fact, and $[(\mathrm{C})]$ follows, given that to create something is to make it exist. (2009: 359 )

It's easy to see why someone might think of the debate about the existence of fictional characters as being trivial, if one accepted the above. But not everyone would. It's not obvious that the premise is true or that the conclusion follows from the premise.

Some metaphysicians have argued that when we utter sentences such as $(\mathrm{P})$ we are in fact engaging in a sort of make-believe (most prominently, Walton 1990). Stuart Brock (2002) opts for a prescriptive view and suggests that we paraphrase such sentences by prefixing them with the intensional operator 'according to the realist fiction'. Schaffer (2009: 36of.) seems to be in favour of giving these fictionalist views a grounding re-interpretation. ${ }^{\circ}$ But I doubt that a fictionalist such as Walton would be happy with this suggestion, even if he accepted the grounding framework. A Waltonian fictionalist might simply disagree with Schaffer on what the facts are, and that it's simply not true that people express what $(P)$ literally says.

In fact, it's not even obvious that $(\mathrm{C})$ is true. Common sense, it seems, would be more likely to deny the truth of $(C)$ than assert it. After all, individual fictional characters are often thought of as paradigm examples of things that don't exist. Metaphysicians who argue against the existence of fictional characters often mo-

29. See also Koslicki (2012).

30. Jason Turner (2016) is not in favour of Schaffer's re-interpretation of previously existing views. 
tivate their position by calling negative existentials such as "Holmes doesn't exist" truisms. But this stands in tension with Schaffer's claim that it's easily shown that Sherlock Holmes exists. As Tim Button points out, "we should expect that our 'ordinary' usage [of nouns] will be subject to tensions which push us in different directions" (2016: 21). Reconciling the two apparently true claims needs work and resolving the tension is not an easy task, but a philosophically deep one. Chris Daly and David Liggins note that "many philosophers think of reflective equilibrium as the correct philosophical method" and "in reflective equilibrium we try to turn our stock of beliefs into as theoretically virtuous a collection as possible" (2014: 463, my emphasis). Indeed the problem of negative existentials has been described as the most pressing challenge for those in favour of fictional entities. ${ }^{31}$ All of this suggests that there is no easy answer to the question of whether fictional characters exist, but that it is something open to debatewhether you accept the grounding framework or are committed to a different meta-ontological view. Metaphysics of fictional characters within the grounding framework then emerges as a rich discipline that asks whether fictional characters exist, whether facts about them are ungrounded or not, and, if they are grounded, what the grounding facts are.

But while I hold that figuring out an answer to whether fictional characters exist is significant, I don't think that accepting that there are such entities makes you a fictional realist. That's, more importantly, because I think metaphysical explanations offer us a way to reduce our ontological commitments to only the ungrounded entities. So, by saying that it's a fact that there are fictional characters we don't offend our desire for desert landscapes, because that desire is sufficiently satisfied at the ungrounded basis. Note how different theorists would answer the question of what we are ontologically committed to.

For the Quinean, to be ontologically committed to Fs means to accept that there are Fs. For Cameron accepting that $F$ s are ungrounded is committing oneself to Fs. According to a grounding theorist such as Fine, accepting that $F$ s are real amounts to ontologically committing oneself to Fs. And for someone like Schaffer, the answer to what it means to be ontologically committed to Fs is the same as for the Quinean: it is to accept that Fs exist. But unlike the Quinean, Schaffer thinks there's an important metaphysical difference between ungrounded and grounded entities.

Though the last three are all considered grounding theorists, my sympathies lie with Cameron and Fine (on one reading of Fine) rather than Schaffer..$^{32}$ In our joint paper Richard Woodward and I (2013) distinguished between deflation-

31. See Walton (2003), Everett $(2005 ;$ 2007). Even Thomasson agrees that this is a serious challenge.

32. But see Cameron (2014) where he embraces the inflationary grounding view. Thanks to an anonymous referee for this journal for bringing my attention to this article. 
ary and inflationary grounding accounts. On the inflationary view, reality divides into grounded and ungrounded entities. It makes sense on this view to talk about 'levels of reality'. Schaffer's view is essentially an inflationary one. The view I prefer is deflationary. Note that on Schaffer's inflationary view, talk of ungrounded and grounded is primarily applied to entities. But on the deflationary view is it primarily attached to representations such as facts, sentences or propositions. Fictional characters, on the deflationary picture, can be called grounded entities because they are referred to or quantified over in the grounded facts. This quote from Jonathan Bennett nicely brings the deflationary commitment of such a grounding theorist to the fore:

The work of any interesting metaphysician involves two or more levels. I do not mean levels of reality: the metaphysicians I am talking about do not describe reality as stratified; rather, they stratify their accounts of it. At the basic level of speech, thought and conceptualization, they express truths that directly reflect the metaphysical situation; at the less basic level, they say things that are still true, but, as stated, are bad pointers to the metaphysical situation, and one needs an account of what their truth amounts to, comes down to, arises from, in terms of facts expressed at the basic level. The non-basic level gets a hearing only because it involves ordinary, familiar ways of saying things. (2001: 147-180)

On the view I defended here, commonsensical claims such as "there are fictional characters" and "Hermione was created by Rowling" are still true, but "bad pointers to the metaphysical situation'. The truth of such claims arises from facts concerning not fictional characters but rather authors, their activities, and their audiences.

The term 'ontological commitment' is a term of philosophical art. The way I conceive of the role of ontological commitment, it is tightly connected to the idea that parsimony is a virtue possessed by theories. 33 Since parsimony favours the theory that postulates fewer kinds of entities, all other things being equal, we should think of ontological commitment as a tie-breaker in the same way. The view I've proposed accepts that fictional characters exist but denies that fictional entities are ungrounded. Since on this view we are not ontologically committed to fictional characters, it's not clear that principles of parsimony would apply where the grounded entities are concerned in the same way as they would where the ungrounded is concerned.34 Having said that, I am not wedded to the

33. For discussion of whether ontological parsimony should to theory choice in philosophy see, e.g., Huemer (2009), Sober (2015), Willard (2014).

34. But see Turner (2016) for why parsimony matters when it comes to the grounded entities as well. Thanks to an anonymous referee for drawing my attention to the article. 
expression 'ontological commitment', so if using the term in this way necessarily leads to confusion, I am quite happy to abstain from using it.

I suspect that parsimony does not carry as much weight when it comes to the grounded entities as it does when it comes to the ungrounded. For example, while we cannot expect metaphysical explanations not to be long and messy since the world may well be complicated and messy, we can reasonably expect a semantical theory that makes sense of our talk and thought about fictional characters to be neat and elegant. But this will have to be the topic of another article.

So, why do I call the view I proposed here an anti-realist view about fictional characters? Just as the term 'ontological commitment' is a term of philosophical art, so is the expression 'anti-realism', and, just as the way we conceive of ontological inquiry changes, so will the meaning of the technical terms. If we think of the distinction of anti-realism and realism about fictional characters as concerning our ontological commitments, as I suggested at the beginning, this means the view I have proposed here is an anti-realist view about fictional characters. Recall, I took anti-realism about fictional characters to mean that we are not ontologically committed to fictional characters. And further that to be ontologically committed to fictional characters amounts to an acceptance that they are ungrounded. Since I deny that fictional entities are ungrounded, I believe I have earned the right to call my view an anti-realist one.

No doubt more needs to be said. But I hope it is acceptable within the limits of this paper that I have given some pointers towards what I consider to be plausible answers.

\section{4 .}

My goal in this paper has been to develop an alternative and in some ways antiQuinean approach to the debate about fictional characters, one which gives a central role to a distinctively metaphysical form of explanation. This isn't as antiQuinean as it seems: after all, the Quinean, too, needs to incorporate a metaphysical notion to give the paraphrase a direction. And with the notion of grounding in place, a theorist who denies the reality of fictional characters is better off concentrating on giving grounding explanations for facts about such things, where the grounding facts don't mention fictional characters anymore.

But the view I defended in this article also differs from Thomasson's view that ontology is easy. While I accept that fictional characters exist, I don't think this gives us sufficient reason to embrace an ontological commitment to them. I then proceeded by sketching what such explanations might look like for various truths about fictional objects, and we saw that it looks promising that such truths can be explained in terms of authors, their acts, and their audiences. I finally at- 
tempted to dispel two related concerns about my proposal. The first worry was that the view I am suggesting doesn't leave any prospect for a metaphysics of fictional characters. But I outlined what metaphysical inquiry into fictional characters would look like on my account and acknowledged the importance of the existence question. The second concern was that the proposed view is not in fact an anti-realist one. This is why I think it is: although the grounding anti-realist accepts commonsensical and theoretical claims about fictional characters, she does not think that they feature in her ontology, since she doesn't take them to be explanatorily basic.

There is, of course, much more to be said about the conception of ontological inquiry that I've deployed in order to develop a novel version of fictional antirealism. But I hope that it's clear that the view is deserving of attention, and that the resulting version of anti-realism it offers is an attractive one.

\section{Acknowledgments}

Many thanks are due to Richard Woodward and Jonathan Schaffer for their invaluable input. I'd also like to thank Ross Cameron, Tim Crane, Matti Eklund, Anthony Everett, Stacie Friend, Manuel García-Carpintero, Dominic Gregory, Kevin Horan, Dan Lopez de Sa, Ed Nettel, Eric Olson, Dominik Perler, Tuomas Tahko, Barbara Vetter, Ken Walton, the brilliant audiences at the Lightness of Being workshop at the University of Uppsala, the Invited Speakers Seminar at the University of Helsinki, the Nature of Fictional Characters workshop at the University of Göttingen, and the PERSP Seminar at the University of Barcelona, as well as two anonymous referees and the copy editor for this journal. 


\section{References}

Barnes, Elizabeth (2014). Going Beyond the Fundamental: Feminism in Contemporary Metaphysics. Proceedings of the Aristotelian Society, 114, 335-351. https://doi. org/10.1111/j.1467-9264.2014.00376.x

Bennett, Jonathan (2001). Learning from Six Philosophers I. Oxford University Press. https:// doi.org/10.1093/0198250924.001.0001

Braun, David (2005). Empty Names, Fictional Names, Mythical Names. Noûs, 39(4), 596631. https://doi.org/10.1111/j.0029-4624.2005.00541.x

Brock, Stuart (2002). Fictionalism about Fictional Characters. Noûs, 36(1), 1-21. https:// doi.org/10.1111/1468-0068.00358

Brock, Stuart (2010). The Creationist Fiction: The Case against Creationism about Fictional Characters. Philosophical Review, 119(3), 337-364. https://doi.org/10.1215/003181082010-003

Button, Tim (2016). Deflationary Metaphysics and Ordinary Language. Synthese. Advance online publication. https://doi.org/10.1007/s11229-016-1212-z

Cameron, Ross (2010). How to Have a Radically Minimal Ontology. Philosophical Studies, 151(2), 249-264. https://doi.org/10.1007/s11098-009-9442-2

Cameron, Ross (2013). How to Be a Nominalist and a Fictional Realist. In Christy Mag Uidhir (Ed.), Art and Abstract Objects (179-196). Oxford University Press. https://doi. org/10.1093/acprof:oso/9780199691494.003.0009

Cameron, Ross (2014). Parts Generate the Whole but Are not Identical to It. In Donald L. M. Baxter and Aaron J. Cotnoir (Eds.), Composition as Identity (90-107). Oxford University Press. https://doi.org/10.1093/acprof:oso/9780199669615.003.0005

Crane, Tim (2008). Sainsbury on Thinking about an Object. Critica, 40(120), 85-95.

Daly, Chris and David Liggins (2014). In Defence of Existence Questions. Monist, 97(7), 46o-478. https://doi.org/10.1093/monist/97.4.460

Dorr, Cian (2005). What We Disagree about When We Disagree about Ontology. In Mark Kalderon (Ed.), Fictionalism in Metaphysics (234-286). Oxford University Press.

Eagle, Antony (2007). Telling Tales. Proceedings of the Aristotelian Society, 107, 125-147. https://doi.org/10.1111/j.1467-9264.2007.00215.x

Epstein, Brian (2015). The Ant Trap: Rebuilding the Foundations of the Social Sciences. Oxford University Press. https://doi.org/10.1093/acprof:oso/9780199381104.001.0001

Evans, Gareth (1982). The Varieties of Reference. Oxford University Press.

Everett, Anthony (2005). Against Fictional Realism. The Journal of Philosophy, 102(12), 624-649. https://doi.org/10.5840/jphil2005102129

Everett, Anthony (2007). Pretense, Existence and Fictional Objects. Philosophy and Phenomenological Research, 74(1), 56-8o. https://doi.org/10.1111/j.1933-1592.2007.00003.x

Field, Hartry (1980). Science without Numbers. Oxford University Press.

Fine, Kit (2001). The Question of Realism. Philosopher's Imprint, 1(1), 1-20.

Fine, Kit (2005). Modality and Tense: Philosophical Papers. Oxford University Press. https:// doi.org/10.1093/0199278709.001.0001

Fine, Kit (2009). The Question of Ontology. In David Chalmers, David Manley, and Ryan Wasserman (Eds.), Metametaphysics (157-177). Oxford University Press.

Forbes, Graeme (2006). Attitude Problems: An Essay on Linguistic Intensionality. Clarendon. https://doi.org/10.1093/acprof:oso/9780199274949.001.0001

Friend, Stacie (2000). Real People in Unreal Contexts: Or Is There a Spy among Us? In 
Anthony Everett and Thomas Hofweber (Eds.), Empty Names, Fiction, and the Puzzles of Nonexistence (183-203). CSLI Publications.

Hanley, Richard (2003). Much Ado about Nothing: Critical Realism Examined. Philosophical Studies, 115(2), 123-147. https://doi.org/10.1023/A:1025093302392

Howell, Robert (1979). Fictional Objects: How They Are and How They Aren't. Poetics, 8(1-2), 129-177. https://doi.org/10.1016/0304-422X(79)90018-4

Huemer, Michael (2009). When is Parsimony a Virtue? Philosophical Quarterly, 59(235), 216-236. https://doi.org/10.1111/j.1467-9213.2008.569.x

Koslicki, Kathrin (2012). Varieties of Ontological Dependence. In Fabrice Correia and Benjamin Schnieder (Eds.), Metaphysical Grounding: Understanding the Structure of Reality (186-213). Cambridge University Press. https://doi.org/10.1017/ CBO9781139149136.008

Kripke, Saul (2013). Reference and Existence. The John Locke Lectures. Oxford University Press. https://doi.org/10.1093/acprof:oso/9780199928385.001.0001

Lewis, David (1978). Truth in Fiction. American Philosophical Quarterly, 15(1), 37-46.

Melia, Joseph (2005). Truthmaking without Truthmakers. In Helen Beebee and Julian Dodd (Eds.), Truthmakers: The Contemporary Debate (67-84). Clarendon. https://doi. org/10.1093/acprof:oso/9780199283569.003.0005

Mikkola, Mari (2016). On the Apparent Antagonism between Feminist and Mainstream Metaphysics. Philosophical Studies, 174(10), 2435-2448. https://doi.org/10.1007/ s11098-016-0732-1

Moltmann, Friederike (2013). The Semantics of Existence. Linguistics and Philosophy, 36(1), 31-63. https://doi.org/10.1007/s10988-013-9127-3

Moltmann, Friederike (2015). Quantification with Intentional and with Intensional Verbs. In Alessandro Torza (Ed.), Quantifiers, Quantifiers, and Quantifiers (141-168). Springer. https://doi.org/10.1007/978-3-319-18362-6_8

Sainsbury, Mark (2009). Fiction and Fictionalism. Routledge.

Sainsbury, Mark (2010). Intentionality Without Exotica. In Robin Jeshion (Ed.), New Essays on Singular Thought (300-318). Oxford University Press. https://doi.org/10.1093/ acprof:oso/9780199567881.003.0011

Salis, Fiora (2013). Fictional Names and the Problem of Intersubjective Identification. Dialectica, 67(3), 283-301. https://doi.org/10.1111/1746-8361.12031

Salmon, Nathan (1998). Nonexistence. Noûs, 32(3), 277-319. https://doi.org/10.1111/00294624.00101

Salmon, Nathan (2002). Mythical Objects. In Joseph Keim-Campbell, Michael O'Rourke and David Shier (Eds.), Meaning and Truth: Investigations in Philosophical Semantics (105-123). Seven Bridges.

Schaffer, Jonathan (2009). On What Grounds What. In David Chalmers, David Manley, and Ryan Wasserman (Eds.), Metametaphysics (347-383). Oxford University Press.

Schaffer, Jonathan (2017). Social Construction as Grounding; Or: Fundamentality for Feminists, a Reply to Barnes and Mikkola. Philosophical Studies, 174(10), 2449-2465. https://doi.org/10.1007/s11098-016-0738-8

Schiffer, Stephen (1996). Language-Created, Language-Independent Entities. Philosophical Topics, 24(1), 149-167. https://doi.org/10.5840/philtopics199624117

Schiffer, Stephen (2003). The Things We Mean. Clarendon. https://doi. org/10.1093/0199257760.001.0001

Schnieder, Benjamin and Tatjana von Solodkoff, Tatjana (2009). In Defence of Fictional 
Realism. Philosophical Quarterly, 59(234), 138-149. https://doi.org/10.1111/j.14679213.2008.583.x

Sider, Theodore (2009). Ontological Realism. In David Chalmers, David Manley, and Ryan Wasserman (Eds.), Metametaphysics (384-423). Oxford University Press.

Sider, Theodore (2011). Writing the Book of the World. Oxford University Press. https://doi. org/10.1093/acprof:oso/9780199697908.001.0001

Sider, Theodore (2017). Substantivity in Feminist Metaphysics. Philosophical Studies, 174(10), 2467-2478. https://doi.org/10.1007/s11098-016-0739-7

Sober, Elliott (2015). Ockham's Razors: A User's Manual. Cambridge University Press. https://doi.org/10.1017/CBO9781107705937

Szabó, Zoltán (2003). Nominalism. In Michael J. Loux and Dean W. Zimmerman (Eds.), The Oxford Handbook of Metaphysics (11-45). Oxford University Press.

Thomasson, Amie (1999). Fiction and Metaphysics. Cambridge University Press. https:// doi.org/10.1017/CBO9780511527463

Thomasson, Amie (2003a). Fictional Characters and Literary Practices. British Journal of Aesthetics, 43(2), 138-157. https://doi.org/10.1093/bjaesthetics/43.2.138

Thomasson, Amie (2003b). Speaking of Fictional Characters. Dialectica, 57(2), 207-226. https://doi.org/10.1111/j.1746-8361.2003.tb00266.x

Thomasson, Amie (2007). Ordinary Objects. Oxford University Press. https://doi. org/10.1093/acprof:oso/9780195319910.001.0001

Turner, Jason (2016). Curbing Enthusiasm about Grounding. Philosophical Perspectives, 3o(1), 366-396. https://doi.org/10.1111/phpe.12087

van Inwagen, Peter (1977). Creatures of Fiction. American Philosophical Quarterly, 14(4), 299-308.

van Inwagen, Peter (1983). Fiction and Metaphysics. Philosophy and Literature, 7(1), 66-77. https://doi.org/10.1353/phl.1983.0059

van Inwagen, Peter (1985). Pretense and Paraphrase. In Patrick McCormick (Ed.), The Reasons of Art (414-422). University of Ottawa Press.

van Inwagen, Peter (2000). Quantification and Fictional Discourse. In Anthony Everett and Thomas Hofweber (Eds.), Empty Names, Fiction and the Puzzles of Non-Existence (235-247). CSLI Press.

van Inwagen, Peter (2003). Existence, Ontological Commitment, and Fictional Entities. In Michael J. Loux and Dean W. Zimmerman (Eds.), Oxford Handbook of Metaphysics (131-157). Oxford University Press.

von Solodkoff, Tatjana (2012). Straightening Priority Out. Philosophical Studies, 161(3), 391-401. https://doi.org/10.1007/s11098-011-9745-y

von Solodkoff, Tatjana (2014a). Fictional Realism and Negative Existentials. In Manuel García-Carpintero and Genoveva Martí (Eds.), Empty Representations: Reference and Non-Existence (333-352). Oxford University Press. https://doi.org/10.1093/acprof:o so/9780199647057.003.0015

von Solodkoff, Tatjana (2014b). Paraphrase Strategies in Metaphysics. Philosophy Compass, 9(8), 570-582. https://doi.org/10.1111/phc3.12150

von Solodkoff, Tatjana and Woodward, Richard (2013). Noneism, Ontology, and Fundamentality. Philosophy and Phenomenological Research, 87(3), 558-583. https://doi. org/10.1111/phpr.12054

von Solodkoff, Tatjana and Woodward, Richard (2018). To Have and to Hold. Philosophical Issues, 27(1), 407-427. https://doi.org/10.1111/phis.12107 
Walton, Kendall (1990). Mimesis as Make-Believe. Harvard University Press.

Walton, Kendall (2000). Existence as Metaphor. In Anthony Everett and Thomas Hofweber (Eds.), Empty Names, Fiction and the Puzzles of Non-Existence (69-94). CSLI Press.

Walton, Kendall (2003). Restricted Quantification, Negative Existentials, and Fiction. Dialectica, 57(2), 239-242. https://doi.org/10.1111/j.1746-8361.2003.tb00268.x

Willard, Mary Beth (2013). Game Called on Account of Fog: Metametaphysics and Epistemic Dismissivism. Philosophical Studies, 164(1), 1-14. https://doi.org/10.1007/ s11098-013-0097-7

Willard, Mary Beth (2014). Against Simplicity. Philosophical Studies, 167(1), 165-181. https://doi.org/10.1007/s11098-013-0228-1

Williams, Robert (2010). Fundamental and Derivative Truths. Mind, 119(473), 103-141. https://doi.org/10.1093/mind/fzp137

Woodward, Richard (2011). Truth in Fiction. Philosophy Compass, 6(3), 158-167. https:// doi.org/10.1111/j.1747-9991.2010.00367.x

Yablo, Stephen (2005). The Myth of the Seven. In Mark Kalderon (Ed.), Fictionalism in Metaphysics (88-115). Oxford University Press. 
